\title{
О.В. Котомина
}

\section{ФУНКЦИОНАЛЬНАЯ МОДЕЛЬ ВЛИЯНИЯ СИСТЕМЫ ВЫСШЕГО ОБРАЗОВАНИЯ НА УСТОЙЧИВОЕ РАЗВИТИЕ РЕГИОНА}

\begin{abstract}
Концепция устойчивого развития (УР) нацелена на сохранение жизни на Земле и обеспечение достойного ее уровня настоящему и будущим поколениям людей, противостоит современным глобальным вызовам. Переход к УР подразумевает пересмотр существующих ценностей в экономической, экологической и социальной сферах жизни общества и совершенствование его институционального базиса. В этой связи именно образование играет наиважнейшую роль, когда в образовательный процесс встроена воспитательная функция, отвечающая за формирование ценностных установок подрастающего поколения, и прогресс в трансформации формальных и неформальных институциональных рамок.

Для реализации этих процессов ООН разработана глобальная программа «Образование в интересах устойчивого развития (ОУР)» и сформулирована одна из специализированных целей в системе из семнадцати целей устойчивого развития, утвержденных ООН на 2016-2030 гг. Высшее образование при этом играет особую роль, так как не только создает и распространяет знания об УР, но и влияет на процесс принятия будущих решений управленцами различного уровня, так как охватывает взрослых людей, уже занимающихся профессиональной деятельностью, или молодых специалистов, стоящих на ее пороге. В этой связи актуальным становится вопрос о том, как системы высшего образования могут влиять на устойчивое развитие. Особенно данный вопрос актуален для регионов, в связи с тем, что региональная система высшего образования, как правило, ориентирована на потребности региона в подготовке профессиональных кадров и проведении научных исследований.

В работе представлена функциональная модель влияния системы высшего образования на устойчивое развитие региона. Новизной модели является то, что она разработана на основе функционального подхода и учитывает взаимное влияние системы высшего образования и внешней среды, в которой она функционирует. Такая модель позволяет расширить методический инструментарий анализа функциональности или дисфункциональности региональной системы высшего образования и понимание каналов ее влияния на устойчивое развитие региона.

Ключевые слова: система высшего образования, устойчивое развитие региона, функция, университет.
\end{abstract}

Высшее образование для устойчивого развития региона. Устойчивое развитие - концепция, которая предполагает удовлетворение потребностей настоящего без ущерба удовлетворению потребностей будущих поколений [1]. Несмотря на наличие большого количества определений устойчивого развития, представленное определение из доклада $\mathrm{OOH}$ «Наше общее будущее» является классическим и наиболее широко распространенным. Важно отметить, что устойчивое развитие учитывает современные глобальные вызовы и потребности будущих поколений, опирается на ценности охранного природо-

(с) Котомина О.В., 2021

Котомина Ольга Викторовна - старший преподаватель департамента менеджмента ФГАОУ ВО «НИУ ВШЭ - Пермь», аспирант экономического факультета ФГАОУ ВО «Пермский государственный национальный исследовательский университет», e-mail: kotominaov@gmail.com. 
пользования, ответственного потребления и этичной деловой практики. УР включает экономические, экологические и социальные аспекты.

Мировым сообществом активно исследуется концепция устойчивого развития социально-экономических систем, однако базовые положения данной концепции рассматриваются, как правило, в общемировом масштабе. Поэтому требуется перенос приоритетов исследования с общемирового на национальный и региональный уровень для обеспечения большей эффективности управления [2].

Качественное образование является одной из семнадцати целей УР, утвержденных ООН на 2016-2030 гг. Высшее образование имеет важное значение для внедрения устойчивого развития. С одной стороны, университет за счет образовательной, экспертной и исследовательской деятельности может создавать и распространять знания об УР, формировать соответствующие ценности. С другой стороны, университет может внедрять концепцию устойчивого развития в собственную деятельность. Осознавая масштаб экономических, экологических и социальных проблем, а также скорость глобальных изменений, университеты создают институциональную основу для перехода к более устойчивому будущему.

Университеты играют особую роль в экономике региона. Региональные университеты ориентированы на потребности региональных предприятий и организаций различных отраслей экономики, органов власти, на реализацию программ высшего и дополнительного образования, востребованных в конкретном регионе, на проведение фундаментальных и прикладных исследований, актуальных для региона.

Таким образом, высшее образование является действенным инструментом, способствующим УР региона [3-5]. Однако российские университеты далеки от переориентации на устойчивое развитие [6]. В связи с этим актуальным является изучение возможных каналов влияния системы высшего образования на устойчивое развитие региона.

Влияние системы высшего образования на устойчивое развитие региона. В узком смысле под системой высшего образования региона можно понимать совокупность расположенных на территории региона университетов, которые обеспечивают широкий по видам, формам и содержанию спектр образовательных, научно-исследовательских, экспертных и других услуг [7].

В широком смысле под региональной системой высшего образования понимается совокупность университетов, органов управления образованием, определяющих образовательную политику в регионе, органов государственной и региональной власти, бизнес-структур и организаций, заинтересованных в подготовке высококвалифицированных специалистов в регионе, конкурентоспособных и мобильных на рынке труда.

Внешние акторы (органы федеральной и региональной власти, предприятия и организации, общество в целом) могут принимать различное по харак- 
теру, объему и глубине участия в реализации функций университетов. При этом оценить вклад каждого актора в полученный результат реализации каждой функции видится проблематичным. В связи с этим в данной работе региональная система высшего образования будет рассматриваться в узком смысле с признанием влияния внешних акторов на функционирование системы высшего образования в целом.

Система высшего образования является частью социально-экономической системы региона. Региональная система высшего образования влияет на социально-экономическую систему региона, но существует и обратное влияние от уровня развития социально-экономической системы зависят возможности и условия развития системы высшего образования.

На рисунке представлена функциональная модель системы высшего образования в интересах устойчивого развития региона, в которой региональная система высшего образования представлена в четком и логичном формате выполняемых функций. Качество выполнения каждой функции определяет качество функционирования системы в целом.

Применение такого подхода обусловлено возможностью комплексной оценки влияния системы высшего образования на устойчивое развитие региона, учитывающей функции этой системы, различные факторы внешней региональной среды и связи между ними, а также возможностью определения на основе такой оценки функциональности или дисфункциональности системы высшего образования региона.

Модель предполагает, что функционирование региональной системы высшего образования в интересах устойчивого развития влияет на показатель устойчивого развития региона как комплексный показатель и в частности на три его составляющих сферы: экономическую, экологическую и социальную.

Процессы глобализации и интернационализации национальных систем, становление новой социально-экономической эпохи требуют трансформации системы высшего образования и переосмысления функций университета, отражающих взаимодействие между образованием, наукой и инновациями, являющимися ключевыми факторами в развитии общества [8]. Рассмотрим подробнее возможные каналы влияния функций современной системы высшего образования на сферы устойчивого развития региона.

Образовательная функция предполагает обучение населения знаниям, умениям, навыкам, востребованным и признанным на рынке труда.

Современные университеты являются центрами создания, накопления и распространения знаний. При этом научно-технический прогресс дает университетам все больше возможностей для распространения знаний (например, онлайн-курсы) и таким образом расширяет контингент предложения образовательных услуг. В этом контексте усиливается конкуренция между университетами на международном уровне. 


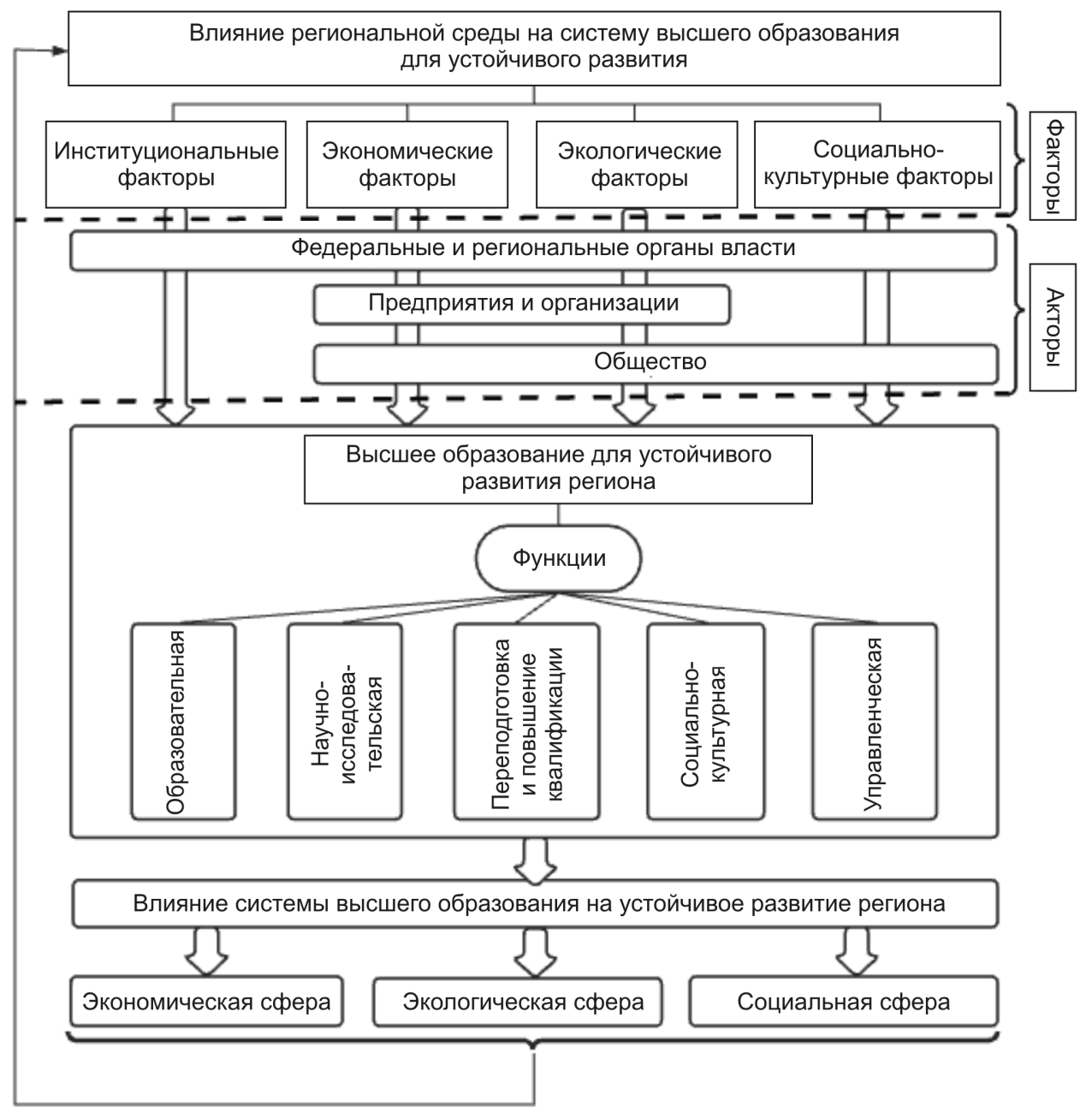

Рис. Функциональная модель системы высшего образования в интересах устойчивого развития региона

Данная функция в большей степени связана с социальной составляющей устойчивого развития, предполагая оказание образовательных услуг в системе человек - человек. Также за счет того, что общество становится более образованным, данная функция оказывает положительное влияние на экономику региона. Так, например, в докладе ОЭСР «Взгляд на образование 2019» было отмечено, что уровень занятости взрослых с высшим образованием на 9 процентных пунктов выше, чем у лиц со средним образованием, и они зарабатывают на $57 \%$ больше [9]. Влияние на экологическую составляющую происходит через ответственное потребление и управление отходами (раздельный сбор, сдача на утилизацию опасных отходов) студентами, выпускниками и работниками университета. 
Научно-исследовательская функция заключается в проведении фундаментальных и прикладных научных исследований, выполнении работ по грантам, реализации совместных проектов с командами исследователей из разных стран, с научно-исследовательскими центрами и предприятиями региона. Данная функция обязательно включает в себя распространение полученных знаний через публикации в научных изданиях российского и международного уровня и научные конференции, проводимые на региональном, всероссийском и международном уровне.

Важно отметить, что, с одной стороны, новые научные ориентиры научно-исследовательской деятельности университетов связаны с направленностью исследований на решение глобальных мировых проблем. В миссиях университетов отчетливо высвечивается стремление к глобальному прорыву в решении общемировых задач: улучшение, изменение мира, решение проблем человечества [10]. С другой стороны, университеты в регионе ориентированы также и на проведение совместно с органами власти и организациями прикладных научных исследований для решения частных региональных проблем. Перспективным направлением для вузов в регионе является создание технопарков, инновационных центров, технополисов на базе вуза, а также активизация взаимодействия с малым, средним и крупным бизнесом посредством выполнения прикладных проектов [11].

Говоря о современных университетах, М. Луковикс и Б. Зути отмечают, что проводимые университетами исследования, разработки и инновации должны быть социально ответственными, т.е. «они должны быть социально приемлемыми, демократическими и вносить вклад в инновационные цели общества» [12].

Научно-исследовательская функция связана с социальной составляющей через налаживание коммуникаций с разными агентами, а также через сглаживание цифрового неравенства путем беспрепятственного и всеобщего доступа к глобальной информации и научным знаниям, что позволяет сократить уровень бедности, маргинализации и социальной изоляции [13]; с экономической составляющей через привлечение грантов в регион, разработку решений по эффективному использованию ограниченных ресурсов, производство новых видов технологичной продукции с высокой долей добавленной стоимости, что стимулирует создание новых рабочих мест и постепенное снижение критической зависимости от зарубежных технологий [13] и т.д. А через внедрение результатов практических исследований, распространение технологий, обеспечивающих более экономное и рациональное использование ограниченных природных ресурсов, энерго- и ресурсосберегающих технологий выстраивается взаимосвязь с экологической составляющей устойчивого развития.

Следующая функция в системе высшего образования - повышение квалификации, переподготовка специалистов - позволяет взрослым людям, уже имеющим образование, совершенствовать свои знания в соответствии с разви- 
тием науки и техники, осваивать новые знания. Инициаторами образовательного процесса могут выступать компании, которые ориентированы на поддержание высокого уровня знаний работников и обогащение человеческого капитала современными актуальными знаниями для поддержания конкурентоспособности компании, или сами работники, ориентированные на актуализацию собственных знаний для качественной работы и поддержания своей конкурентоспособности на рынке труда. Следует особо выделить данную функцию, поскольку, с одной стороны, набор образовательных возможностей для взрослых людей ограничен, а с другой стороны, формирование новых ценностей у взрослых требует особых усилий. При этом исследования показывают, что внедрение принципов устойчивого развития в практику управления крайне важно для современных российских предприятий (см., например, [14]).

Данная функция связана с социальной составляющей через передачу знаний и формирование определенных ценностей, с экономической составляющей через рост производительности труда и совершенствование бизнеспроцессов организаций, и с экологической составляющей устойчивого развития через использование принципов УР как в работе организаций, так и в повседневной личной жизни.

Социально-культурная функция предполагает формирование определенных ценностей и норм поведения человека в обществе. В частности, современные исследователи достаточно активно обсуждают «третью миссию» университета, которая заключается в его влиянии на общество. «В настоящее время университет занимает место в обществе, далеко выходящее за рамки подготовки кадров и развития научного знания. Университет становится и важным центром управления социальными процессами, и мощным социальным ресурсом, активно влияющим на духовные процессы общества и непосредственно оказывающим воздействие на экономическую, политическую и иные сферы деятельности» [15]. «Третья миссия» связана с подготовкой студентов к жизни в гражданском обществе, умением оказывать влияние на общественную и политическую жизнь, совмещением обучения и общественно полезной деятельности, получением знаний через практику, приобретением партнеров и полезного жизненного опыта [16].

В широком смысле цель высшего образования для устойчивого развития состоит в создании условий для становления специалистов, понимающих новые явления и процессы общественной жизни, владеющих системой ценностей, культурных и этических принципов, норм поведения, готовых к социально ответственной профессиональной деятельности и непрерывному образованию в динамично меняющемся мире [17]. Современный мир обогатит новое поколение профессионалов, способных нести ответственность за результаты своей деятельности, ориентированных на созидание социальных благ, готовых проявлять заботу о других [10]. 
Социально-культурная функция связана с социальной составляющей устойчивого развития через формирование определенных ценностей в обществе, с экологической составляющей устойчивого развития через следование данным ценностям в повседневной жизни большим количеством человек, а также с экономической составляющей через выбор технологий и ресурсов в пользу более экологичных вариантов.

Управленческая функция заключается в обеспечении руководством университета наилучших условий функционирования системы высшего образования.

В условиях ограниченных ресурсов, с учетом особенностей российской системы высшего образования и современных вызовов глобальной среды, именно руководители университета через выстраивание приоритетов, распределение ресурсов и принятие управленческих решений определяют целевые показатели и создают условия для их достижения.

В исследовании факторов, влияющих на качество образования, в котором опрашивались студенты, преподаватели и работодатели, было выявлено, что ответственность руководства университета является значимым внутренним фактором для всех категорий опрошенных [18]

Данная функция связана с экономической составляющей устойчивого развития региона через создание рабочих мест, обеспечение конкурентоспособной заработной платы, привлечение на территорию грантов, уплату налогов и т.д., с социальной составляющей через обеспечение международного обмена среди студентов и преподавателей, с экологической составляющей через обеспечение условий для более экологичного поведения самого университета, а также через экспертную помощь по этому вопросу другим организациям региона.

Таким образом, можно сделать вывод, что все функции университета могут оказывать влияние на все три составляющие устойчивого развития региона.

Как было сказано ранее, в реализацию функций системы высшего образования вовлечены различные внешние агенты, к которым можно отнести органы федеральной и региональной власти, предприятия и организации и общество в целом (местное сообщество, общественные объединения, абитуриенты и родители и т.д.) $[19,20]$. Целесообразно рассмотреть, как именно они могут участвовать в реализации основных функций университета.

В соответствии со статьей 6 Федерального закона от 29.12.2012 № 273-Ф3 «Об образовании в Российской Федерации», федеральные органы государственной власти в сфере образования осуществляют полномочия лицензирования, государственной аккредитации и государственного контроля организаций, осуществляющих образовательную деятельность по образовательным программам высшего образования. Таким образом, федеральные органы власти определяют политику в сфере высшего образования, финансируют государственные университеты, а также контролируют их деятельность. Поэтому университеты имеют в некоторой степени двойное подчинение. С одной сто- 
роны, управление и контроль высшего образования осуществляется на федеральном уровне, с другой стороны, региональная система высшего образования ориентирована на решение приоритетных социально-экономических задач региона. При этом исследователи (например, Л.В. Волошина и Н.В. Харина) отмечают отсутствие разработанной федеральной программы по внедрению регионального компонента содержания образования в образовательный процесс [21]. Это может накладывать определенные ограничения на решение университетом региональных задач по устойчивому развитию.

Региональные органы власти, в свою очередь, могут выступать заказчиками в подготовке специалистов, выделять средства для грантов и конкурсов среди научно-педагогических работников (что важно для их удержания на территории региона), могут быть партнерами в проведении значимых для региона прикладных научных исследований и внедрении их результатов, модераторами при обеспечении взаимодействия университетов, организаций и органов власти в совместных проектах. В то же время отсутствие заинтересованности региональных органов власти, недопонимание важности концепции устойчивого развития с их стороны может выступать для университетов серьезным препятствием для реализации целей высшего образования в интересах устойчивого развития региона.

Следующий участник, который вовлечен в реализацию функций высшего образования в интересах устойчивого развития региона, - это предприятия и организации.

Одной из важных проблем последних периодов является разновекторное сосуществование рынка образования и рынка труда - несоответствие требований работодателей и набора умений и знаний, предлагаемых в образовательных программах. Пересмотр подходов к реализации программ и повышение качества трудоустройства выпускников приводят к наращиванию корпоративного партнерства между высшим образованием и бизнесом, а вследствие этого - появлению новых форм взаимодействия с целью обеспечения согласования интересов высшего образования как поставщика образовательного продукта и инвестиций бизнеса в развитие человеческого потенциала, что в свою очередь сказывается на росте общей эффективности и отдачи от инвестиций в образование [22].

Участие предприятий и организаций в реализации функций системы высшего образования региона может заключаться в следующем:

1) формирование требований к выпускникам университетов, которые выходят на рынок труда;

2) запрос на целевое обучение специалистов для собственных нужд;

3) участие в учебном процессе и взаимодействие со студентами (проведение специалистами компаний лекций, практико-ориентированных семинаров, привлечение студентов на практику и т.д.);

4) участие в научно-исследовательской деятельности. 
Важную роль в реализации концепции устойчивого развития играет общество в целом. Влияние на выполняемые университетом функции осуществляется через спрос на высшее образование, запрос на подготовку конкретных специалистов, через цели и ценности общества.

Полученная информация о функциях университета, основных акторах и влиянии на разные сферы устойчивого развития региона обобщена в табл. 1.

Таблица 1

Влияние функций системы высшего образования на устойчивое развитие региона

\begin{tabular}{|c|c|c|c|}
\hline Функция СВО & Экономическая сфера & Экологическая сфера & Социальная сфера \\
\hline $\begin{array}{l}\text { Образовательная } \\
\text { функция } \\
\text { Акторы: Универ- } \\
\text { ситет, Предпри- } \\
\text { ятия и организа- } \\
\text { ции, Общество }\end{array}$ & $\begin{array}{l}\text { Рост производительно- } \\
\text { сти труда и повышение } \\
\text { заработной платы }\end{array}$ & $\begin{array}{l}\text { Внедрение технологий } \\
\text { ответственного произ- } \\
\text { водства и управления } \\
\text { отходами (раздельный } \\
\text { сбор, сортировка, пе- } \\
\text { реработка и т.д.) }\end{array}$ & $\begin{array}{l}\text { Рост уровня образова- } \\
\text { ния населения и воз- } \\
\text { можностей использова- } \\
\text { ния «социального лиф- } \\
\text { та», повышение уровня } \\
\text { доходов и улучшение } \\
\text { качества жизни людей }\end{array}$ \\
\hline \begin{tabular}{|l|} 
Научно-исследова- \\
тельская функция \\
Акторы: Универ- \\
ситет, Предпри- \\
ятия и организа- \\
ции, Федеральные \\
и региональные \\
органы власти
\end{tabular} & $\begin{array}{l}\text { Привлечение исследо- } \\
\text { вательских грантов в } \\
\text { регион, разработка ре- } \\
\text { шений по эффективно- } \\
\text { му использованию ог- } \\
\text { раниченных ресурсов, } \\
\text { привлечение инвести- } \\
\text { ций и стимулирование } \\
\text { инновационной дея- } \\
\text { тельности, изменение } \\
\text { структуры производст- } \\
\text { ва и рост добавленной } \\
\text { стоимости }\end{array}$ & $\begin{array}{l}\text { Внедрение результатов } \\
\text { исследований в дея- } \\
\text { тельность организа- } \\
\text { ций, ускорение эколо- } \\
\text { гизации производст- } \\
\text { венных и сервисных } \\
\text { процессов, разработка } \\
\text { новых экологически } \\
\text { чистых технологий и } \\
\text { материалов }\end{array}$ & $\begin{array}{l}\text { Усиление интеграции } \\
\text { университета с бизне- } \\
\text { сом, органами власти, } \\
\text { мировым научным со- } \\
\text { обществом в решении } \\
\text { актуальных социаль- } \\
\text { ных задач }\end{array}$ \\
\hline \begin{tabular}{|l} 
Повыление ква- \\
лификации, про- \\
фессиональная \\
переподготовка \\
специиалистов \\
Акторы: Универ- \\
ситет, Предпри- \\
ятия и организации
\end{tabular} & $\begin{array}{l}\text { Поддержание высокого } \\
\text { уровня производитель- } \\
\text { ности труда, ускорение } \\
\text { процессов внедрения } \\
\text { новых технологий и } \\
\text { совершенствования } \\
\text { бизнес-процессов }\end{array}$ & $\begin{array}{l}\text { Совершенствование } \\
\text { системы управления } \\
\text { отходами, ускорение } \\
\text { процессов экологиза- } \\
\text { ции хозяйственной } \\
\text { деятельности }\end{array}$ & $\begin{array}{l}\text { Вовлечение взрослого } \\
\text { населения и лиц, при- } \\
\text { нимающих решения, } \\
\text { в процессы реализации } \\
\text { концепции устойчивого } \\
\text { развития }\end{array}$ \\
\hline $\begin{array}{l}\text { Социально-куль- } \\
\text { турная функция } \\
\text { Акторы: Универ- } \\
\text { ситет, Общество }\end{array}$ & $\begin{array}{l}\text { Формирование культу- } \\
\text { ры ответственного } \\
\text { производства, инвести- } \\
\text { рования и управления } \\
\text { у бизнес-сообщества }\end{array}$ & $\begin{array}{l}\text { Формирование ценно- } \\
\text { стей УР и понимания } \\
\text { гражданами необхо- } \\
\text { димости экологически } \\
\text { ответственного пове- } \\
\text { дения в повседневной } \\
\text { жизни }\end{array}$ & $\begin{array}{l}\text { Формирование культу- } \\
\text { ры ответственного по- } \\
\text { требления и быта } \\
\text { у населения }\end{array}$ \\
\hline
\end{tabular}


Окончание табл. 1

\begin{tabular}{|c|c|c|c|}
\hline Функция СВО & Экономическая сфера & Экологическая сфера & Социальная сфера \\
\hline \begin{tabular}{|l|} 
Управленческая \\
функимя \\
Акторы: Универ- \\
ситет, Федераль- \\
ные и региональ- \\
ные органы власти
\end{tabular} & $\begin{array}{l}\text { Создание рабочих } \\
\text { мест, обеспечение эко- } \\
\text { номического роста } \\
\text { региональной эконо- } \\
\text { мики на новой техно- } \\
\text { логической основе }\end{array}$ & $\begin{array}{l}\text { Снижение экологиче- } \\
\text { ской интенсивности и } \\
\text { экологической нагруз- } \\
\text { ки производства и по- } \\
\text { требления }\end{array}$ & $\begin{array}{l}\text { Снижение социаль- } \\
\text { ной напряженности, } \\
\text { активизация соци- } \\
\text { ального диалога, } \\
\text { расширение про- } \\
\text { грамм международ- } \\
\text { ного сотрудничества } \\
\text { с участием студентов } \\
\text { и преподавателей, } \\
\text { активизация эксперт- } \\
\text { ной деятельности } \\
\text { университетов в сфе- } \\
\text { ре рационального } \\
\text { природопользования }\end{array}$ \\
\hline
\end{tabular}

Таким образом, функции системы высшего образования региона через прямое и косвенное воздействие оказывают значимое влияние на устойчивое развитие региона в целом, а также на его экономическую, экологическую и социальную сферы в частности.

Влияние факторов внешней среды на функционирование системы высшего образования. Выше было рассмотрено, как реализация функций системы высшего образования влияет на устойчивое развитие региона. Важно принимать во внимание и обратное влияние, то, как региональная среда со своими историческими, культурными, ресурсными и социально-экономическими особенностями влияет на систему высшего образования, создавая определенные условия, возможности, а в некоторых случаях и ограничения для функционирования системы высшего образования. Достигнутый уровень устойчивого развития региона будет определять решения органов власти, требования работодателей, ценности общества и через них требования к системе высшего образования в интересах устойчивого развития региона.

В качестве факторов внешней среды, которые могут оказать влияние на функционирование системы высшего образования, в контексте данной статьи взяты экономические, экологические и социально-культурные факторы. Кроме того, в силу особенностей управления и контроля российской системы высшего образования в модель включены институциональные факторы, которые связаны с решениями органов власти в отношении условий функционирования высшего образования.

В табл. 2 рассмотрено, как факторы внешней среды могут оказывать влияние на различные функции системы высшего образования. 
Влияние факторов внешней среды на функционирование системы высшего образования

\begin{tabular}{|c|c|c|c|c|c|}
\hline \multirow[b]{2}{*}{ Факторы } & \multicolumn{5}{|c|}{ Функция } \\
\hline & $\begin{array}{c}\text { образова- } \\
\text { тельная }\end{array}$ & $\begin{array}{c}\text { научно- } \\
\text { исследова- } \\
\text { тельская } \\
\end{array}$ & $\begin{array}{c}\text { переподготовка } \\
\text { и повышение } \\
\text { квалификации }\end{array}$ & $\begin{array}{l}\text { социально- } \\
\text { культурная }\end{array}$ & $\begin{array}{c}\text { управленче- } \\
\text { ская }\end{array}$ \\
\hline $\begin{array}{l}\text { Институ- } \\
\text { циональ- } \\
\text { ные }\end{array}$ & $\begin{array}{l}\text { Утверждение } \\
\text { образователь- } \\
\text { ных стандартов } \\
\text { (требований к } \\
\text { содержанию } \\
\text { образователь- } \\
\text { ных программ) }\end{array}$ & $\begin{array}{l}\text { Определение } \\
\text { приоритетных } \\
\text { направлений } \\
\text { исследований }\end{array}$ & $\begin{array}{l}\text { Размещение } \\
\text { государственно- } \\
\text { го (регионально- } \\
\text { го) заказа на } \\
\text { обучение спе- } \\
\text { циалистов и } \\
\text { контроль за его } \\
\text { реализацией }\end{array}$ & $\begin{array}{l}\text { Реализация } \\
\text { федеральных } \\
\text { и региональ- } \\
\text { ных проектов } \\
\text { и программ с } \\
\text { участием ра- } \\
\text { ботников ву- } \\
\text { зов }\end{array}$ & $\begin{array}{l}\text { Установление } \\
\text { лицензион- } \\
\text { ных требова- } \\
\text { ний к услови- } \\
\text { ям реализа- } \\
\text { ции образова- } \\
\text { тельной дея- } \\
\text { тельности }\end{array}$ \\
\hline $\begin{array}{l}\text { Экономи- } \\
\text { ческие }\end{array}$ & $\begin{array}{l}\text { Установление } \\
\text { количества } \\
\text { бюджетных } \\
\text { мест и размера } \\
\text { субсидий го- } \\
\text { сударствен- } \\
\text { ным вузам. } \\
\text { Экономиче- } \\
\text { ские возмож- } \\
\text { ности населе- } \\
\text { ния оплачи- } \\
\text { вать свое } \\
\text { обучение и } \\
\text { обучение сво- } \\
\text { их детей } \\
\end{array}$ & $\begin{array}{l}\text { Финансирова- } \\
\text { ние предпри- } \\
\text { ятиями и орга- } \\
\text { нами государ- } \\
\text { ственной } \\
\text { власти науч- } \\
\text { ных исследо- } \\
\text { ваний. } \\
\text { Проведение } \\
\text { научных фо- } \\
\text { румов и содей- } \\
\text { ствие между- } \\
\text { народному } \\
\text { научному со- } \\
\text { трудничеству }\end{array}$ & $\begin{array}{l}\text { Финансирова- } \\
\text { ние программ } \\
\text { переподготовки } \\
\text { и повышения } \\
\text { квалификации } \\
\text { кадров. } \\
\text { Заключение до- } \\
\text { говоров на целе- } \\
\text { вое обучение } \\
\text { студентов }\end{array}$ & $\begin{array}{l}\text { Ценность } \\
\text { высшего об- } \\
\text { разования для } \\
\text { населения, } \\
\text { определяю- } \\
\text { щая величину } \\
\text { спроса на об- } \\
\text { разовательные } \\
\text { программы }\end{array}$ & $\begin{array}{l}\text { Обеспечение } \\
\text { вузов вне- } \\
\text { бюджетными } \\
\text { доходами }\end{array}$ \\
\hline $\begin{array}{l}\text { Экологи- } \\
\text { ческие }\end{array}$ & $\begin{array}{l}\text { Совершенст- } \\
\text { вование со- } \\
\text { держания об- } \\
\text { разовательных } \\
\text { программ } \\
\text { (экологизация } \\
\text { высшего } \\
\text { образования) } \\
\end{array}$ & \begin{tabular}{|l|} 
Проведение \\
исследований, \\
направленных \\
на решение \\
экологических, \\
экономических \\
и социальных \\
проблем \\
\end{tabular} & $\begin{array}{l}\text { Формирование у } \\
\text { взрослых обу- } \\
\text { чающихся зна- } \\
\text { ний, умений и } \\
\text { навыков в сфере } \\
\text { экологизации } \\
\text { производства }\end{array}$ & $\begin{array}{l}\text { Распростра- } \\
\text { нение ценно- } \\
\text { стей и норм } \\
\text { экологически } \\
\text { и социально } \\
\text { ответственно- } \\
\text { го поведения }\end{array}$ & $\begin{array}{l}\text { Ответствен- } \\
\text { ное потреб- } \\
\text { ление ресур- } \\
\text { сов и } \\
\text { управление } \\
\text { отходами } \\
\text { внутри уни- } \\
\text { верситета } \\
\end{array}$ \\
\hline $\begin{array}{l}\text { Социаль- } \\
\text { но-куль- } \\
\text { турные }\end{array}$ & $\begin{array}{l}\text { Совершенст- } \\
\text { вование со- } \\
\text { держания об- } \\
\text { разовательных } \\
\text { программ } \\
\text { (гуманитари- } \\
\text { зация высшего } \\
\text { образования) }\end{array}$ & \begin{tabular}{|l} 
Проведение \\
исследований \\
в партнерстве \\
с внешними \\
агентами по \\
широкому \\
спектру ЦУР
\end{tabular} & $\begin{array}{l}\text { Формирование } \\
\text { у взрослых } \\
\text { обучающихся } \\
\text { понимания зна- } \\
\text { чимости соци- } \\
\text { альной ответст- } \\
\text { венности } \\
\text { бизнеса }\end{array}$ & $\begin{array}{l}\text { Рост ценности } \\
\text { высшего об- } \\
\text { разования } \\
\text { в обществе. } \\
\text { Функциони- } \\
\text { рование } \\
\text { «социального } \\
\text { лифта» }\end{array}$ & $\begin{array}{l}\text { Сотрудниче- } \\
\text { ство вузов } \\
\text { с вузами- } \\
\text { партнерами, } \\
\text { предпри- } \\
\text { ятиями } \\
\text { и органами } \\
\text { власти }\end{array}$ \\
\hline
\end{tabular}


Таким образом, можно видеть, что факторы внешней среды через прямое и косвенное воздействие оказывают значительное влияние на функционирование системы высшего образования.

$$
* * *
$$

Высшее образование признается драйвером устойчивого развития территории. Однако в существующих исследованиях достаточно мало внимания уделяется тому, как университеты оказывают влияние на экономику региона, его экологическую и социальную сферы, т.е. на его устойчивое развитие. Существующие системы оценки часто сосредоточены на внутренних показателях деятельности системы высшего образования и не включают показателей внешнего влияния [4]. Разработанная функциональная модель влияния системы высшего образования на устойчивое развитие региона призвана преодолеть этот теоретический разрыв.

Теоретическая значимость разработки представленной функциональной модели региональной системы высшего образования в интересах устойчивого развития региона заключается в определении основных функций, которые эта система должна выполнять, с учетом влияния факторов внешней среды. Такая модель позволит расширить методический инструментарий анализа функциональности или дисфункциональности системы высшего образования и каналов ее влияния на устойчивое развитие региона.

\section{Список литературы}

1. Доклад Всемирной комиссии по вопросам окружающей среды и развития «Наше общее будущее» [Электронный ресурс] / ООН. - N.Y., 1987. - 412 с. URL: http://www.un.org/ru/ga/pdf/brundtland.pdf (дата обращения: 21.02.2021).

2. Третьякова Е.А., Осипова М.Ю. Сочетание статического и динамического подходов в оценке устойчивого развития региональных социальноэкономических систем // Вестник Пермского университета. Экономика. 2016. - № 2 (29). - С. 79-92.

3. A review of commitment and implementation of sustainable development in higher education: results from a worldwide survey / R. Lozano, K. Ceulemans, M. AlonsoAlmeida, D. Huisingh, F.J. Lozano, T. Waas, J. Hugé // Journal of Cleaner Production. 2015. - Vol. 108. - P. 1-18. doi https://doi.org/10.1016/j.jclepro.2014.09.048

4. Assessing the impacts of higher education institutions on sustainable development-an analysis of tools and indicators / F. Findler, N. Schönherr, R. Lozano, B. Stacherl // Sustainability. - 2019. - Vol. 11, № 1. - P. 1-19.

5. Giesenbauer B., Müller-Christ G. University 4.0: Promoting the Transformation of Higher Education Institutions toward Sustainable Development // Sustainability. - 2020. - Vol. 12, № 3371. - P. 1-27. 
6. Kankovskaya A.R. Higher Education for Sustainable Development: Challenges in Russia // Procedia CIRP. - 2016. - Vol. 48. - P. 449-453. doi https:// doi.org/10.1016/j.procir.2016.03.153

7. Шевченко О.М. Мониторинг развития системы высшего образования региона // Обучение и воспитание: методики и практика. - 2015. - № 20. C. 149-153.

8. Васецкая Н.О. Функции университета в экономике знаний // Бизнес. Образование. Право. - 2019. - № 2. - С. 86-89.

9. OECD 2019. Education at a Glance 2019: OECD Indicators / OECD Publishing. - Paris, 2019. - URL: http:/www.oecd.org/education/education-at-a-glance/ (дата обращения: 10.01.2021).

10. Емельянова И., Волосникова Л. Функции современных университетов: сравнительный анализ миссий отечественных и зарубежных вузов // Университетское управление: практика и анализ. - 2018. - Т. 22, № 1 (113). C. 83-92. DOI 10.15826/umpa.2018.01.008

11. Резник Г.А., Пономаренко Ю.С., Курдова М.А. Функции вуза: новые возможности развития [Электронный ресурс] // Мир науки. - 2014. - № 4. URL: http://mir-nauki.com (дата обращения: 10.01.2021).

12. Lukovics M., Zuti B. New functions of universities in century XXI towards “fourth generation" universities // Academia. edu. - 2017. - Vol. 9. - P. 33-49.

13. Варавва М.Ю. Усиление внешних позитивных эффектов научного знания в новой экономике // Теоретическая экономика. - 2020. - № 7. - С. 42-50.

14. Alferova T., Shilova E., Tretiakova E. Methodical approaches to measuring sustainable development of industrial enterprises // European Research Studies Journal. - 2015. - Vol. 18, № 3. - P. 115-128. DOI: 10.35808/ersj/459

15. Продиблох Н.Е. Социальная роль университета в современном трансформирующемся обществе // Вестник Майкопского государственного технологического университета. - 2018. - № 1. - С. 87-93.

16. Мальковец Н.В. Третья функция университета: потребность или обязанность // Society and Security Insights. - 2019. - Т. 2, № 3. - С. 177-184.

17. Худин А.Н. Управленческие механизмы устойчивого развития образовательного процесса в университете // Педагогическое образование и наука. 2018. - № 1. - C. 7-11.

18. Есенбаева Г.А., Какенов К.С., Какенова У.К. Оценка факторов, влияющих на качество образования в вузе // Международный журнал экспериментального образования. - 2016. - № 2-2. - С. 241-244.

19. Саввинов В.М., Стрекаловский В.Н. Учет интересов стейкхолдеров в управлении развитием образования // Вестник международных организаций. Образование, наука, новая экономика. - 2013. - Т. 8, № 1. - С. 87-99.

20. Клемешев А.П., Кудряшова Е.В., Сорокин С.Э. Стейкхолдерский подход в реализации «третьей миссии» университетов // Балтийский регион. 2019. - Т. 11, № 4. - С. 114-135. 
21. Волошина Л.В., Харина Н.В. Особенности региональной образовательной системы и ее устойчивость // Научно-педагогическое обозрение. Pedagogical Review. - 2015. - № 1 (7). - C. 102-110.

22. Олейникова О.Н., Редина Ю.Н. Макротренды развития системы высшего образования в мире // Вестник Воронежского государственного университета. Проблемы высшего образования. - 2018. - № 3. - С. 13-28.

\section{References}

1. Doklad Vsemirnoi komissii po voprosam okruzhaiushchei sredy i razvitiia "Nashe obshchee budushchee" [Report of the World Commission on Environment and Development "Our common future"]. UN, 04.08.1987, 412 p., available at: http://www.un.org/ru/ga/pdf/brundtland.pdf (accessed 21.02.2021).

2. Tret'iakova E.A., Osipova M.Iu. Sochetanie staticheskogo i dinamicheskogo podkhodov $\mathrm{v}$ otsenke ustoichivogo razvitiia regional'nykh sotsial'no-ekonomicheskikh system [Combination of static and dynamic approaches to assessing sustainable development of regional socio-economic systems]. Vestnik Permskogo universiteta. Seriia: ekonomika, 2016, no. 2 (29), pp. 79-92.

3. Lozano R., Ceulemans K., Alonso-Almeida M., Huisingh D., Lozano F.J., Waas T., Hugé J. A review of commitment and implementation of sustainable development in higher education: Results from a worldwide survey. Journal of Cleaner Production, 2015, vol. 108, pp. 1-18. DOI: 10.1016/j.jclepro.2014.09.048.

4. Findler F., Schönherr N., Lozano R., Stacherl B. Assessing the impacts of higher education institutions on sustainable development-an analysis of tools and indicators. Sustainability, 2019, no. 1 (1), pp. 1-19.

5. Giesenbauer B., Müller-Christ G. University 4.0: Promoting the transformation of higher education institutions toward sustainable development. Sustainability, 2020, vol. 12, no. 3371, pp. 1-27.

6. Kankovskaya A.R. Higher education for sustainable development: Challenges in Russia. Procedia CIRP, 2016, vol. 48, pp. 449-453. DOI: 10.1016/j.procir.2016.03.153.

7. Shevchenko O.M. Monitoring razvitiia sistemy vysshego obrazovaniia regiona [Monitoring of the higher education system development in the region]. Obuchenie i vospitanie: Metodiki i praktika, 2015, no. 20, pp. 149-153.

8. Vasetskaia N.O. Funktsii universiteta $\mathrm{v}$ ekonomike znanii [The functions of the university in the knowledge economy]. Biznes. Obrazovanie. Pravo, 2019, no. 2, pp. 86-89.

9. OECD 2019. Education at a glance 2019: OECD indicators. Paris, OECD Publishing, available at: http://www.oecd.org/education/education-at-a-glance/ (accessed 10.01.2021). 
10. Emel'ianova I., Volosnikova L. Funktsii sovremennykh universitetov: sravnitel'nyi analiz missii otechestvennykh i zarubezhnykh vuzov [Functions of modern universities: Comparative analysis of missions of international and national institutions]. Universitetskoe upravlenie: praktika $i$ analiz, 2018, vol. 22, no. 1 (113), pp. 83-92. DOI: 10.15826/umpa.2018.01.008.

11. Reznik G.A., Ponomarenko Iu.S., Kurdova M.A. Funktsii vuza: novye vozmozhnosti razvitiia [Functions of the university: New development opportunities]. Mir nauki, 2014, no. 4, available at: http://mir-nauki.com (accessed 10.01.2021).

12. Lukovics M., Zuti B. New functions of universities in century XXI towards "fourth generation" universities. Academia.edu, 2017, vol. 9, pp. 33-49.

13. Varavva M.Iu. Usilenie vneshnikh pozitivnykh effektov nauchnogo znaniia $\mathrm{v}$ novoi ekonomike [Strengthening external positive effects of scientific knowledge in the new economy]. Teoreticheskaia ekonomika, 2020, no. 7, pp. 42-50.

14. Alferova T., Shilova E., Tretiakova E. Methodical approaches to measuring sustainable development of industrial enterprises. European Research Studies Journal, 2015, vol. 18, no. 3, pp. 115-128. DOI: 10.35808/ersj/459.

15. Prodiblokh N.E. Sotsial'naia rol' universiteta $v$ sovremennom transformiruiushchemsia obshchestve [Social role of a university in the modern transforming society]. Vestnik Maikopskogo gosudarstvennogo tekhnologicheskogo universiteta, 2018, no. 1, pp. 87-93.

16. Mal'kovets N.V. Tret'ia funktsiia universiteta: potrebnost' ili obiazannost' [The third function of the university: The need or the duty]. Society and Security Insights, 2019, vol. 2, no. 3, pp. 177-184.

17. Khudin A.N. Upravlencheskie mekhanizmy ustoichivogo razvitiia obrazovatel'nogo protsessa $\mathrm{v}$ universitete [Management mechanisms of sustainable development in the educational process at the university]. Pedagogicheskoe obrazovanie i nauka, 2018, no 1. pp. 7-11.

18. Esenbaeva G.A., Kakenov K.S., Kakenova U.K. Otsenka faktorov, vliiaiushchikh na kachestvo obrazovaniia $\mathrm{v}$ vuze [Assessment of factors affecting the quality of education at the universities]. Mezhdunarodnyi zhurnal eksperimental'nogo obrazovaniia, 2016, no. 2-2, pp. 241-244.

19. Savvinov V.M., Strekalovskii V.N. Uchet interesov steikkholderov v upravlenii razvitiem obrazovaniia [Meeting stakeholders' needs through effective university management]. Vestnik mezhdunarodnykh organizatsii: obrazovanie, nauka, novaia ekonomika, 2013, vol. 8, no. 1, pp. 87-99.

20. Klemeshev A.P., Kudriashova E.V., Sorokin S.E. Steikkholderskii podkhod v realizatsii "tret'ei missii" universitetov [Stakeholder approach to the implementation of the "third mission" of universities]. Baltiiskii region, 2019, vol. 11, no. 4, pp. 114-135.

21. Voloshina L.V., Kharina N.V. Osobennosti regional'noi obrazovatel'noi sistemy i ee ustoichivost [Special features of the regional educational systems and its sustainability]. Pedagogical Review, 2015, no. 1 (7), pp. 102-110. 
22. Oleinikova O.N., Redina Iu.N. Makrotrendy razvitiia sistemy vysshego obrazovaniia v mire [Macro trends in the development of the higher education system in the world]. Vestnik Voronezhskogo gosudarstvennogo universiteta. Seriia: problemy vysshego obrazovaniia, 2018, no. 3, pp. 13-28.

Оригинальность $76 \%$

Получено 16.03.2021 Принято 29.04.2021 Опубликовано 30.09.2021

\author{
O.V. Kotomina
}

\title{
FUNCTIONAL MODEL OF THE HIGHER EDUCATION SYSTEM IMPACT ON A REGION'S SUSTAINABLE DEVELOPMENT
}

\begin{abstract}
The concept of sustainable development (SD) is aimed at preserving life on Earth and ensuring a decent level of life for the present and future generations. It also addresses modern global challenges. The transition to SD implies a revision of existing values in the economics, ecology and social life. In this regard, education plays the most important role because it is responsible for the formation of the attitudes of a younger generation, and progress in the transformation of formal and informal institutional frameworks.

In order to realize these processes The UN has developed the global program "Education for Sustainable Development" (ESD) and formulated one of the specialized goals in the system of seventeen sustainable development goals approved by the UN for 2016-2030. Higher education plays a special role there, since it not only creates and disseminates knowledge about SD, but also influences the process of making future decisions by managers of various levels. In doing so, the question of how higher education systems can influence sustainable development becomes topical. This issue is especially relevant for the regions since that the regional system of higher education, as a rule, is focused on the needs of the region in training professional personnel and conducting scientific research.

The paper presents a functional model of the higher education system impact on the region sustainable development. The novelty of the model is that it is developed on the basis of a functional approach and takes into account the mutual influence of the higher education system and the external environment in which it operates. Such a model will expand the methodological tools for analyzing the functionality or dysfunctionality of the regional higher education system and understanding the channels of its influence on the sustainable development of the region.

Keywords: higher education system, sustainable development of the region, function, university.
\end{abstract}

Olga V. Kotomina - Senior Lecturer, Management Department, National Research University Higher School of Economics, Perm branch, Perm, Russia, e-mail: kotominaov@gmail.com.

Received 16.03.2021 Accepted 29.04.2021 Published 30.09.2021 